\title{
METABOLIC SYNDROME - AN EMERGING RISK FACTOR FOR CHRONIC KIDNEY DISEASE
}

\author{
ASHWINI SHENAI, SAVITHA G \\ Department of Biochemistry, Saveetha Dental College, Saveetha Institute of Medical and Technical Sciences, Saveetha University, Chennai, \\ TamilNadu, India. Email: drsavitha80@gmail.com
}

Received: 08 January 2018, Revised and Accepted: 28 February 2018

\section{ABSTRACT}

Objective: Metabolic syndrome (MetS) is a common health problem worldwide. According to third national health and nutrition examination survey criteria, about 47 million people have MetS. It is defined as having three or more of the following five risk factors including abdominal obesity, increased triglyceride levels, low-density lipoprotein cholesterol level, elevated blood pressure, and elevated fasting glucose levels. These components of MetS are major risk factors for the development of chronic kidney disease (CKD) also. CKD is a major public problem and it is a major risk factor for the development of cardiovascular disease. Hence, the aim of the current study was to evaluate the association between MetS and CKD.

Methods: A total of 50 patients reporting to Saveetha Dental College and Hospitals were enrolled into the study which includes 25 patients with MetS and 25 healthy individuals. $5 \mathrm{~mL}$ of venous blood was collected and centrifuged. Then, it is analyzed for fasting blood sugar (FBS), serum triglycerides, serum urea, and creatinine using the standard kit method. The data obtained were subjected to statistical analysis using the SPSS software.

Results: The mean body mass index, FBS, serum creatinine, and triglyceride levels were higher in MetS patients in comparison to healthy individuals. The mean body mass index (BMI), FBS, serum urea, serum creatinine, and triglyceride levels in the control group and MetS group were 27.75 \pm 3.67 , $84.8 \pm 12.5,17.52 \pm 5.2,0.91 \pm 0.17$, and $96.5 \pm 60.13$ and $35.14 \pm 4.25,108.8 \pm 34.69,21.4 \pm 5.9,1.0 \pm 0.14$, and $239.76 \pm 51.21$, respectively. There was a significant difference in the mean BMI, FBS, urea, creatinine, and triglyceride levels of the above group.

Conclusion: Serum urea and creatinine levels were significantly higher in MetS individuals. Hence, MetS could be a one of the risk factors for the development of CKD.

Keywords: Metabolic Syndrome, Chronic Kidney Disease, Urea, Creatinine.

(C) 2018 The Authors. Published by Innovare Academic Sciences Pvt Ltd. This is an open access article under the CC BY license (http://creativecommons. org/licenses/by/4. 0/) DOI: http://dx.doi.org/10.22159/ajpcr.2018.v11i6.24658

\section{INTRODUCTION}

Metabolic syndrome (MetS) previously called syndrome $\mathrm{X}$ is defined by a constellation of interconnected physiological, biochemical, clinical, and metabolic factors that directly increases the risk of cardiovascular disease, type 2 diabetes mellitus, and all cause of mortality [1,2]. MetS is a state of chronic low-grade inflammation as a consequence of complex interplay between genetic and environmental factors. Insulin resistance, visceral adiposity, atherogenic dyslipidemia, endothelial dysfunction, genetic susceptibility, elevated blood pressure, hypercoagulable state, and chronic stress are the several factors which constitute the MetS [3-5].

There are currently two major definitions for MetS provided by the International Diabetes Federation (IDF) and the revised National Cholesterol Education Program, respectively.

\section{IDF [6]}

Central adiposity (waist circumference $\geq 90 \mathrm{~cm}$ for men, $\geq 80 \mathrm{~cm}$ for women) and two or more of the following:

- Fasting triglycerides (TGL) $>150 \mathrm{mg} / \mathrm{dL}$ or on specific medication

- HDL cholesterol $<40 \mathrm{mg} / \mathrm{dL}$ and $<50 \mathrm{mg} / \mathrm{dL}$ for men and women, respectively, or on specific medication

- Blood pressure $>130 \mathrm{~mm}$ systolic or $>85 \mathrm{~mm}$ diastolic or previous diagnosis or on specific medication

- Fasting plasma glucose $\geq 100 \mathrm{mg} / \mathrm{dL}$ or previously diagnosed type 2 diabetes.

National Cholesterol Education Program and Adult Treatment Panel III (NCEP: ATP III)

Three or more of the following

- Central obesity - waist circumference $>102 \mathrm{~cm}(\mathrm{M}),>88 \mathrm{~cm}(\mathrm{~F})$

- Hypertriglyceridemia - TGL $\geq 150 \mathrm{mg} / \mathrm{dL}$ or specific medication
- Low HDL cholesterol - $<40 \mathrm{mg} / \mathrm{dL}$ and $<50 \mathrm{mg} / \mathrm{dL}$ for men and women, respectively, or on specific medication

- Hypertension - blood pressure $\geq 130 \mathrm{~mm}$ systolic or $\geq 85 \mathrm{~mm}$ diastolic or on specific medication

- Fasting plasma glucose - $\geq 100 \mathrm{mg} / \mathrm{dL}$ or on specific medication previously diagnosed type 2 diabetes.

Despite MetS is associated with many disorders, it has been clearly associated with chronic kidney disease (CKD) also. Each component of MetS has been associated with both CKD incidence and progression [7]. Major component of MetS is insulin resistance. Insulin is an anti-inflammatory hormone. Hence, insulin resistance leads to inflammation, oxidative stress, and renal insufficiency $[8,9]$. Each and every component of MetS increases the oxidative stress and reactive oxygen species which leads to renal insufficiency and CKD $[9,10]$.

CKD is recognized as a major public health problem. It is defined as a glomerular filtration rate $<60 \mathrm{~mL} / \mathrm{min} / 1.73 \mathrm{~m}^{2}$ and/or markers of kidney damage for at least 3 months. It is assessed by estimating serum creatinine concentration and the urine albumin concentration [11-13]. The major causes for the development of CKD are hypertension, diabetes, obesity, and other causes are anemia, hyperphosphatemia, high plasma C-reactive protein and fibrinogen, accumulation of endogenous inhibitors of nitric oxide synthase, and high sympathetic activity $[14,15]$.

The major causes for the development of CKD are the major components of the development of MetS also. Hence, the aim of this study was evaluation of the association between MetS and CKD. 
Table 1: BMI, FBS, TGL, urea, and creatinine levels in two groups

\begin{tabular}{llll}
\hline Parameters & Mean \pm SD & p value \\
\cline { 2 - 3 } & Control & $\begin{array}{l}\text { Metabolic Syndrome } \\
\text { (MetS) }\end{array}$ & \\
\hline BMI & $27.75 \pm 3.67$ & $35.14 \pm 4.25$ & 0.0001 \\
FBS & $84.8 \pm 12.5$ & $108.8 \pm 34.69$ & 0.002 \\
TGL & $96.6 \pm 60.13$ & $239.76 \pm 51.21$ & 0.0001 \\
Urea & $17.52 \pm 5.2$ & $21.4 \pm 5.9$ & 0.007 \\
Creatinine & $0.91 \pm 0.17$ & $1.0 \pm 0.14$ & 0.047 \\
\hline
\end{tabular}

BMI: Body mass index, FBS: Fasting blood sugar, TGL: Triglycerides

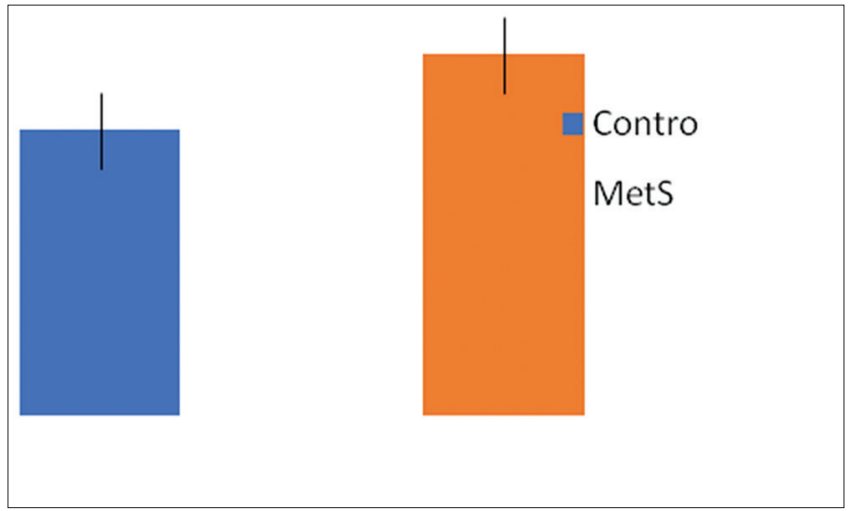

Fig. 1: Mean body mass index level in two groups

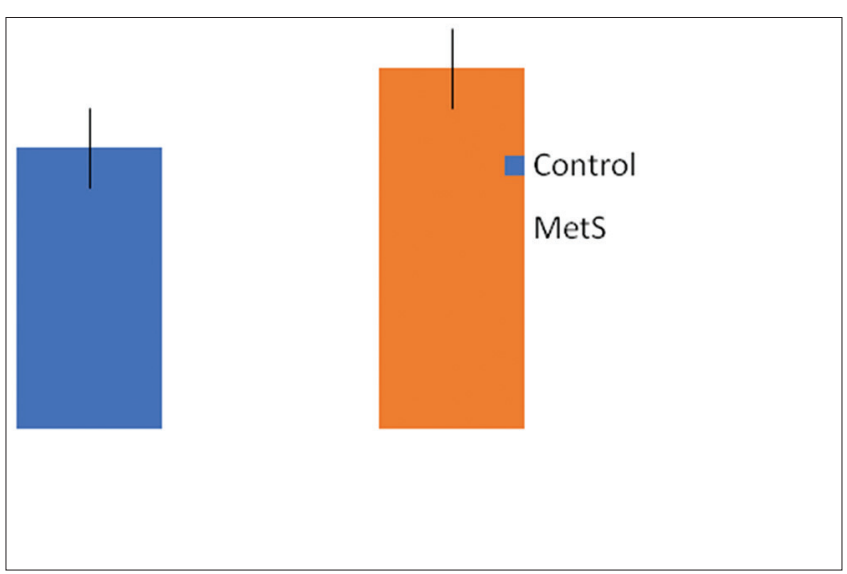

Fig. 2: Mean fasting blood sugar levels in two groups

\section{METHODS}

Patients were selected from those attending the Outpatient Department of Saveetha Dental College and Hospitals and divided into two groups as follows:

- Group I - normal healthy individuals - 25 individuals

- Group II - patients with MetS - 25 individuals.

Inclusion criteria

- Individuals with the age group of 35-55 years.

- Individuals with type 2 diabetes mellitus (fasting blood sugar [FBS] $\geq 100 \mathrm{mg} / \mathrm{dL}$ ).

- Individual with normal body mass index (BMI) (18.9-24.9) and obese BMI $(\geq 30)$.

- Serum TGL levels more than $150 \mathrm{mg} / \mathrm{dL}$.

Exclusion criteria

- Individuals with other systemic illness such as cardiovascular disease, renal failure, stroke, and endocrine illness.

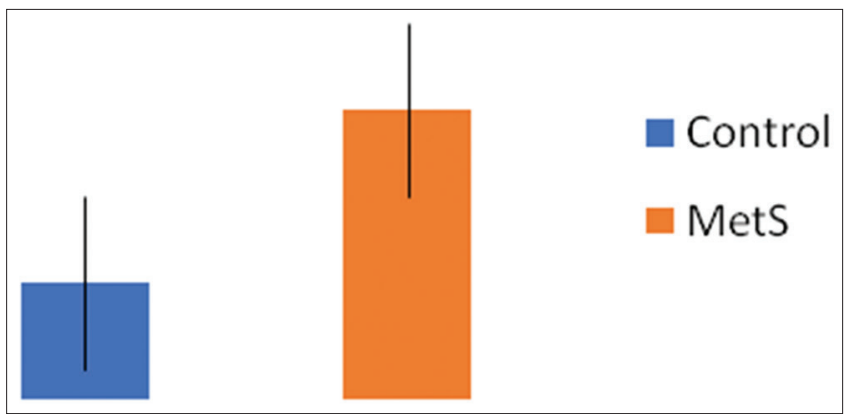

Fig. 3: Mean triglycerides levels in two groups

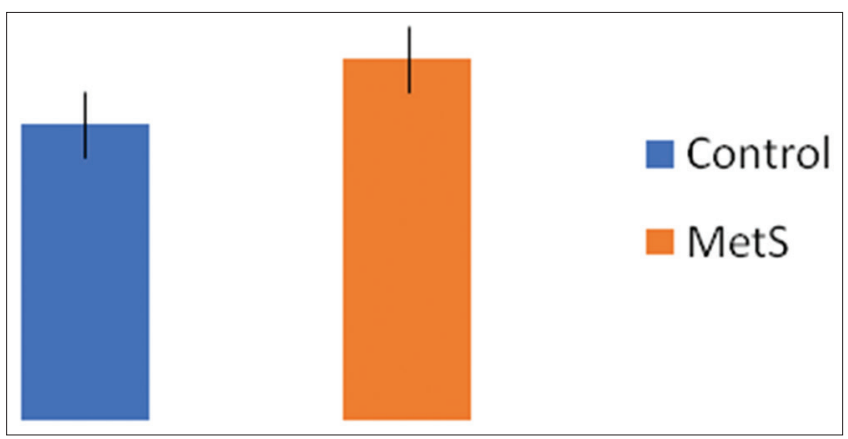

Fig. 4: Mean urea levels in two groups

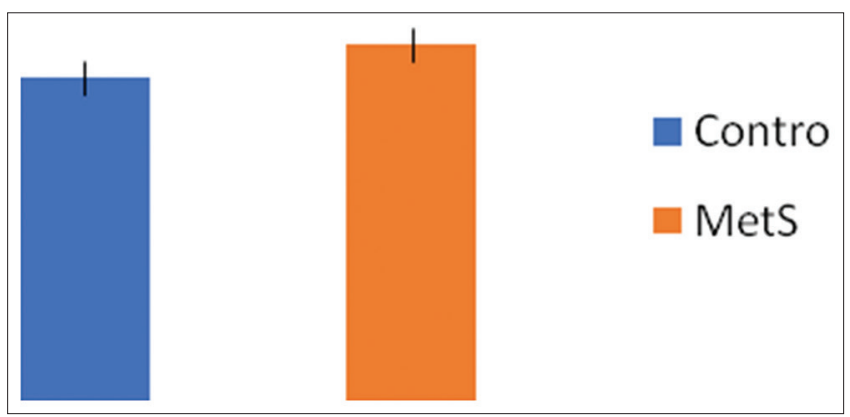

Fig. 5: Mean creatinine levels in two groups

- Individuals with acute illness like fever.

- Immunocompromised individuals.

\section{Sample collection}

Informed consent was obtained from the patient before sample collection. $5 \mathrm{~mL}$ of fasting venous blood was collected and distributed in plain collection tubes and centrifuged in $3000 \mathrm{rpm}$ for serum. Then, serum was separated, and then, it is analyzed for FBS by GOD-POD method, serum TGL by colorimetric enzymatic method, serum urea by urease method, and creatinine by Jaffe's method using ERBA CHEM 5 plus analyzer.

\section{RESULTS}

All the data were analyzed using SPSS package. Student $t$-test analysis was done to find out significant differences between the two groups. All the tests were considered statistically significant at $p<0.05$ level.

\section{DISCUSSION}

The results of this study revealed that there is a significant difference in mean BMI, FBS, TGL, urea, and creatinine levels of the normal control group and MetS group. 
Mean BMI level in control and MetS groups is $27.75 \pm 3.67$ and $35.14 \pm 4.25$, respectively (Table 1 and Fig. 1). Mean serum FBS level in control and MetS groups is $84.8 \pm 12.5$ and $108.8 \pm 34.69$, respectively (Table 1 and Fig. 2). Mean serum TGL level in control and MetS groups is $96.5 \pm 60.13$ and 239.76 \pm 51.21 , respectively (Table 1 and Fig. 3). Mean serum urea level in control and MetS groups is $17.52 \pm 5.2$ and $21.4 \pm 5.9$, respectively (Table 1 and Fig. 4). Mean serum creatinine level in control and MetS groups is $0.91 \pm 0.17$ and $1.0 \pm 0.14$, respectively (Table 1 and Fig. 5).

There was a significant difference between mean BMI, FBS, and TGL levels. That indicates right selection of individuals in both the groups. There was a statistically significant difference between mean serum urea $(p=0.007)$ and mean serum creatinine $(p=0.047)$ levels also.

Our results provide evidence for a positive correlation between urea, creatinine levels in control and MetS individuals. That indicates MetS individuals are prone to develop CKD [16]. Many studies show renal dysfunction becomes apparent long before the appearance of hypertension or diabetes in MetS.

In increased BMI (obesity), there is increased flux of free fatty acids into the liver leading to excessive hepatic production of TGL which leads to hypertriglyceridemia. And also, adipocytes secrete inflammatory cytokines such as tumor necrosis factor- $\alpha$, interleukin- 6 , and C-reactive protein $[17,18]$. Hypertriglyceridemia itself causes for insulin resistance. In diabetes mellitus, increased fasting glucose level leads to hyperinsulinemia and insulin resistance, which leads to excessive release of inflammatory cytokines, which cause glomerular membrane thickening, endothelial dysfunction, renin-aldosterone system activation, oxidative stress, and elevated plasminogen activator inhibitor-1. Ultimately leads to glomerulosclerosis, tubulointerstitial injury, and CKD [19-21].

\section{CONCLUSION}

The present study shows urea and creatinine levels were consistently higher in MetS individuals. These data have indicated that MetS increases the risk of CKD through multiple pathways. Hence, early identification and treatment of individual components of MetS may reduce the risk of the development of CKD. Hence, MetS could be emerging risk factor for the development of CKD.

\section{REFERENCES}

1. Kaur J. A comprehensive review on metabolic syndrome. Cardiol Res Pract 2014;2014: Article ID: 943162.

2. Nerkar D, Mukherjee A, Metha BK, Banerjee S. Metabolic syndrome associated complications. Int J Pharm Pharm Sci 2015;7 Supple7:22-5.

3. Cornier MA, Dabelea D, Hernandez TL, Lindstrom RC, Steig AJ, Stob NR, et al. The metabolic syndrome. Endocr Rev 2008;29:777-822.

4. Srikanthan K, Feyh A, Visweshwar H, Shapiro JI, Sodhi K. Systemic review of metabolic syndrome biomarkers: A panel for early detection, management, and risk stratification in west Virginian Population. Int J Med Sci 2016;13 Supple 1:25-38.

5. Lusis AJ, Attie AD, Reue K. Metabolic syndrome: From epidemiology to systems biology. Nat Rev Gen 2008;9:819-30.

6. Kassi E, Pervanidou P, Kaltsas G, Chrousos G. Metabolic syndrome: Definitions and controversies. BMC Med 2011;9:48.

7. Prasad GV. Metabolic syndrome and chronic kidney disease: Current status and future directions. World J Nephrol 2014;3:210-9.

8. Locatelli F, Pozzoni P, Del Vecchio L. Renal manifestations in the metabolic syndrome. J Am Soc Nephrol 2006;17:S81-5.

9. Laguardia HA, Hamm LL, Chen J. The metabolic syndrome and risk of chronic kidney disease: Pathophysiology and intervention strategies. J Nutr Metab 2012;2012:652608.

10. Williams JD, Woods F. Insulin resistance, the metabolic syndrome and renal failure-is there a special problem for patients treated with peritoneal Dialysis. Eur Endocrinol 2006;2:1-5.

11. Zoccali C, Vanholder R, Massy ZA, Ortiz A, Sarafidis P, Dekker FW, et al. The systemic nature of CKD. Nat Rev Nephrol 2017;13:344-58.

12. Zoccali C, Kramer A, Jager KJ. Chronic kidney disease and end-stage renal disease. A review produced to contribute to the report- the status of health in the European Union: Towards a healthier Europe. Clin Kidney J 2000;3 Supple 3:213-24.

13. Vassalotti JA, Centor R, Turner BJ, Greer RC, Choi M, Sequist TD, et al. Practical approach to detection and management of chronic kidney disease for the primary care clinician. Am J Med 2016;129:153-62.

14. Levin A. Identification of patients and risk factors in chronic kidney disease-Evaluating risk factors and therapeutic strategies. Nephrol Dial Transplant 2001;16 Suppl 7:57-60.

15. Ejerblad E, Fored CM, Lindblad P, Fryzek J, McLaughlin JK, Nyrén O, et al. Obesity and risk for chronic renal failure. J Am Soc Nephrol 2006; $17: 1695-702$

16. Singh AK, Kari JA. Metabolic syndrome and chronic kidney disease. Curr Opin Nephrol Hypertens 2013;22:198-203.

17. Stenvinkel P, Zoccali C, Ikizler TA. Obesity in CKD-What should Nephrologist Know? J Am Soc Nephrol 2013;24 Supple 11:1727-36.

18. Gopala A, Sharma VK, Ganti SS. Rosiglitazone-a journey that never completed. Int J Pharm Pharm Sci 2010;2 Suppl 2:7-9.

19. Kopple JD. Obesity and chronic kidney disease. J Ren Nutr 2010;20:S29-30.

20. Bhowmik D, Tiwari SC. Metabolic syndrome and chronic kidney disease. Indian J Nephrol 2008;18:1-4.

21. Luk AO, So WY, Ma RC, Kong AP, Ozaki R, Ng VS, et al. Metabolic syndrome predicts new onset of chronic kidney disease in 5,829 patients with type 2 diabetes: A 5-year prospective analysis of the Hong Kong diabetes registry. Diabetes Care 2008;31:2357-61. 